\title{
L. The thermodynamics of cryohydrates
}

\section{J. Parker B.A.}

To cite this article: J. Parker B.A. (1888) L. The thermodynamics of cryohydrates, Philosophical Magazine Series 5, 25:156, 406-409, DOI: 10.1080/14786448808628204

To link to this article: http://dx.doi.org/10.1080/14786448808628204

册 Published online: 29 Apr 2009.

Submit your article to this journal $2 \pi$

Џ Article views: 3

Q View related articles $₫$ 


\section{$\left[\begin{array}{ll}406 & ]\end{array}\right.$}

L. The Thermodynamics of Cryohydrates. By J. PARKER, B.A., late Scholar of St. John's College, Cambridge*.

DR. GUTHRIE has found that when a dilute saline solution, formed by dissolving a salt in water or any other liquid, is subjected to reduction of temperatare, the ice formed is perfectly fresh, until a certain temperature is reached, which depends only on the natures of the salt and liquid employed, and not on their relative proportions. The solution then freezes, without further reduction of temperature, into a solid homogeneous brine. Dr. Guthrie has also found that the final solution thus obtained, which he calls a "cryohydrate," is of the same strength whatever may have been the strength of the dilute solution with which we started.

Again, he has found that the lowest temperature obtainable by means of a "cryogen," i.e. a freezing mixture of salt and ice, is the freezing-point of the corresponding cryohydrate.

These experimental results have been obtained at atmospheric pressure, but we shall suppose them to be true at any pressure.

We at once infer that at the freezing-point of the cryohydrate, the salt and pure ice are neutral to each other; in other words, a saturated solution is then in stable equilibrium with pure ice. There is, therefore, only one stable solution possible at this temperature, viz. the cryohydrate itself.

At any temperature above the freezing-point of the cryohydrate, and below the freezing-point of the pure liquid, there may be any number of stable solutions, the strongest being a saturated solution, and the weakest in stable equilibrium with pure ice.

Analytically, let $\dot{\phi}, \psi$ be the thermodynamic potentials at constant pressure of unit weights of the salt and ice, respectively, at any temperature between the freezing-points of the cryohydrate and of the pure liquid.

Also let the weakest stable solution contain a weight $m_{1}$ of the salt, and a weight $m_{2}$ of the liquid. Its thermodynamic potential will be

$$
\Phi=m_{1} f_{1}+m_{2} f_{2},
$$

where $f_{1}, f_{2}$ are homogeneous in $m_{1}$ and $m_{2}$ and of degree 0 .

But the solution is in stable equilibrium with pure ice, and not with the salt; hence;

$$
f_{1}<\phi, \quad f_{2}=\psi \text {. }
$$

* Communicated by the Author. 
Therefore,

$$
\begin{aligned}
\Phi & =m_{1} f_{1}+m_{2} \psi \\
& <m_{1} \phi+m_{2} \psi . . . \quad . \quad . \quad .
\end{aligned}
$$

Again, if a saturated solution contains a weight $M_{1}$ of the salt, and a weight $\mathbf{M}_{2}$ of the liquid, its thermodynamic potential will be

$$
\Phi^{\prime}=\mathrm{M}_{1} \mathrm{~F}_{1}+\mathrm{M}_{2} \mathrm{~F}_{2},
$$

where

$$
\mathrm{F}_{1}=\phi, \quad \mathrm{F}_{2}<\psi
$$

therefore

$$
\begin{aligned}
\Phi^{\prime} & =\mathrm{M}_{1} \phi+\mathrm{M}_{2} \mathrm{~F}_{2} \\
& <\mathrm{M}_{1} \phi+\mathrm{M}_{2} \psi .
\end{aligned}
$$

At the freezing-point of the cryohydrate these two solutions are identical with the cryohydrate itself; and we therefore have

$$
\left.\begin{array}{l}
\Phi=m_{1} \phi_{0}+m_{2} \psi_{0} \\
\Phi^{\prime}=M_{1} \phi_{0}+M_{2} \psi_{0}
\end{array}\right\} \quad \text {. . . . . }
$$

where $\phi_{0}$ and $\psi_{0}$ are the values of $\phi$ and $\psi$ at this temperature.

The solutions we have been studying may be conveniently represented by a diagram. Take three rectangular axes, and let the axis of $x$ denote the temperature, the axis of $y$ the pressure, and the axis of $z$ the quantity $h \equiv \frac{m_{1}}{m_{2}}$, so that $h$ is
the strength of the solution.

The weakest and strongest stable solutions will be represented in the diagram by two surfaces which meet along the freezing line of the cryohydrate, and all other stable solutions will be represented by points lying between these two surfaces.

Our principal object in this paper is to find the effect of pressure upon the freezing-point and composition of the cryohydrate. For the former purpose we make use of the important equations (3).

Thus, let us suppose that at any point $(p, t)$ on the freezing line of the cryohydrate $(v, \mathrm{U}, \mathrm{S}, \Phi)$ represent respectively the volume, energy, entropy, and thermodynamic potential at constant pressure of unit mass of the cryohydrate, and let $\left(v_{1}, \mathrm{U}_{1}, \mathrm{~S}_{1}, \Phi_{1}\right)$ be respectively the sums of the volumes, energies, entropies, and thermodynamic potentials at the same pressure and temperature of the salt and ice of which the cryohydrate is composed.

\section{E 2}


Then we have by (3), Also

$$
\Phi=\Phi_{1} .
$$

$$
\Phi=\mathrm{E}(\mathrm{U}-t \mathrm{~S})+p v, \quad \Phi_{1}=\mathrm{E}\left(\mathrm{U}_{1}-t \mathrm{~S}_{1}\right)+p v_{1},
$$

where $\mathrm{E}$ is the mechanical equivalent of heat.

Again, if the salt and ice be placed in contact with each other, and the temperature kept slightly above the freezingpoint of the cryohydrate, the liquid cryohydrate will be formed, and if $Q$ is the heat absorbed during the process, we must have, since $\Phi=\Phi_{1}$,

$$
\mathrm{Q}=t .\left(\mathrm{S}-\mathrm{S}_{1}\right) \cdot \cdot \cdot \cdot \cdot \cdot \cdot
$$

If we move to a consecutive point $(p+\delta p, t+\delta t)$ on the freezing line, an indefinitely small quantity of ice (or salt) may separate out from the cryohydrate; but whether it does so or not, the changes in $\Phi, \Phi_{1}$ will be respectively

But by (3)

$$
\left.\begin{array}{c}
\delta \Phi=v . \delta p-\mathrm{S} . \delta t \\
\delta \Phi_{1}=v_{1} . \delta p-\mathrm{S}_{1} . \delta t
\end{array}\right\}
$$

hence

$$
\delta \Phi=\delta \Phi_{1} ;
$$

$$
\left(v-v_{1}\right) . \delta p=\left(\mathrm{S}-\mathrm{S}_{1}\right) . \delta t
$$

and, therefore, by (4),

$$
\frac{\mathrm{Q}}{t}=\left(v-v_{1}\right) \cdot \frac{\delta p}{\delta t} \quad \cdot \quad \cdot \quad . \quad . \quad .
$$

We may notice, generally, that the freezing-point of the cryohydrate is depressed or raised by pressure, according as the liquid employed expands or contracts in the act of freezing.

In particular, the freezing-point of the cryohydrate of an aqueous solution of sodium chloride is lowered by pressure by almost exactly the same amount as the freezing-point of pure water.

We will now give reasons for believing that the composition of a cryohydrate is independent of the pressure. For suppose, if possible, that along the freezing line of the cryohydrate, $h$ increases with $p$.

At any pressure $p$, let the temperature of the cryohydrate be reduced below its freezing-point, and then let the pressure increase if $\frac{\delta p}{\delta t}$ is negative along the freezing line, but if $\frac{\delta p}{\delta t}$ is positive, let the pressure decrease.

Referring to the diagram we see that, sooner or later, the 
solid cryohydrate must melt into an unstable solution. The improbability of this event leads us to conclude that $h$ cannot increase with $p$. Similarly we may reason that $h$ cannot deciease as $p$ increases. A cryohydrate must therefore be regarded as a body of definite chemical composition, and not as a mere solution in which the proportions of salt and ice depend upon various accidents.

This property of a cryohydrate has already been noticed by Dr. Guthrie, but he has not examined the effects of pressure.

Again, Duhem has shown that when a dilute solution, formed by dissolving any salt in water, is reduced in temperature until the pure ice appears, then increase of pressure causes some of the ice to melt, or, in analytical language, $\frac{d_{t} h}{d p}$ is negative for the weakest stable solution.

If, however, the solution is formed by dissolving the salt in a liquid, like acetic acid, which contracts whilst freezing, then $\frac{d_{t} h}{d p}$ is positive.

As $h$ is constant along the freezing line of the cryohydrate, it follows that in the former case $\frac{\delta p}{\delta t}$ is negative, and in the latter case positive.

It is now evident that when a salt is dissolved in water, the cryohydrate expands in the act of freezing, and its meltingpoint is lowered by pressure, whereas, when a salt is dissolved in a liquid, like acetic acid, which contracts whilst freezing, the cryohydrate also contracts whilst freezing, and its meltingpoint is raised by pressure.

LI. Experiments with Soap-bubbles. By C. V. Bors, A.R.S.M., Demonstrator of Physics at the Science Schools, South Kensington*.

\section{[Plate II.]}

7 TOUGH none of the experiments $I$ am about to describe 1 depend upon any property of a soap-film which is not perfectly well known and understood, yet they serve to illustrate in a striking and beautiful manner the behaviour of bubbles under special circumstances, and so as lecture-experjments simply I hope they may be considered worthy of the attention of the Physical Society.

* Communicated by the Physical Society : read April 14, 1888. 